\title{
Diversity of long-legged flies (Diptera, Dolichopodidae) of the Balkan Mountains (Bulgaria and Serbia)
}

\author{
Mihail Kechev \\ Forest Research Institute, Bulgarian Academy of Sciences, 132 St Kliment Ohridski Blvd, Sofia, Bulgaria, \\ mkechev@gmail.com; https://orcid.org/0000-0002-9852-5184
}

\begin{abstract}
The present paper gives information about 61 dolichopodid species distributed in the Balkan Mountains, Bulgaria and Serbia. Twenty-two species, collected from 13 localities, are new to the Balkan Mountains and seven of them (Dolichopus longicornis, Hercostomus chetifer, Medetera pallipes, M. muralis, Neurigona quadrifasciata, N. pallida and Sciapus costea) are new to the fauna of Bulgaria. Medetera pallipes and Sciapus costea are also new to the Balkan Peninsula. Thus, the total number of known species of the family Dolichopodidae for Bulgaria increases to 204.
\end{abstract}

Keywords: Balkan Mountains, Bulgaria, Dolichopodidae, fauna, new records, Serbia

\section{Introduction}

The dolichopodid fauna of the Balkan Mountain range (Stara Planina Mts) has not been subject of special study up to now. Some authors gave separate reports from the Balkan Mountains: Beschovski (1964, 1967, 1971 and 2013) listed nine species, Beschovski \& Dzhambazhov (2002) reported one species, Olejniček \& Barták (1997) listed one species from Dolni Chiflik, Grichanov (2016) recorded 24 species from the Serbian part of the Stara Planina Mts, while Kechev (2017) reported seven dolichopodids collected from the Sinite Kamani Natural Park and Yantra River near Veliko Tarnovo.

The main purpose of this paper is to provide new records of Dolichopodidae for the Stara Planina Mts and to make a review of the known species of the family for the mountain up to now.

\section{Material and methods}

The material for the present work was collected by means of sweep net by the author and by means of Mal- aise traps by M. Langourov, T. Ljubomirov and I. Todorov from 13 localities in the studied area (Fig. 1). After collection, the adults were put in vials containing $75 \%$ ethanol. The species were sorted in the laboratory, using a stereo microscope Carl Zeiss. For the determination of dolichopodids were used identification guides by Parent (1938), d'Assis Fonseca (1978), Grichanov (2007) and Negrobov \& Stackelberg (1969). The faunistic list includes the following information: name of the species, material (male and female) and site of collection. The material presented in this paper as new to the Balkan Mountains is housed in Mihail Kechev's collection in the Forest Research Institute, Bulgarian Academy of Sciences, Department of Forest Entomology, Phytopathology and Game Fauna, Sofia, Bulgaria.

Sites of collection:

Site 1: Chiprovtsi, 26.VII.2020, 43.365971 N 22.847796 E, $550 \mathrm{~m}$ a.s.1., sweeping net, $\mathrm{M}$. Kechev. (Fig. 2).

Site 2: Varshets, 10.V-15.VI.2005, $43.199808 \mathrm{~N}$ 23.275018 E, $400 \mathrm{~m}$ a.s.1., Malaise trap, M. Langourov. 

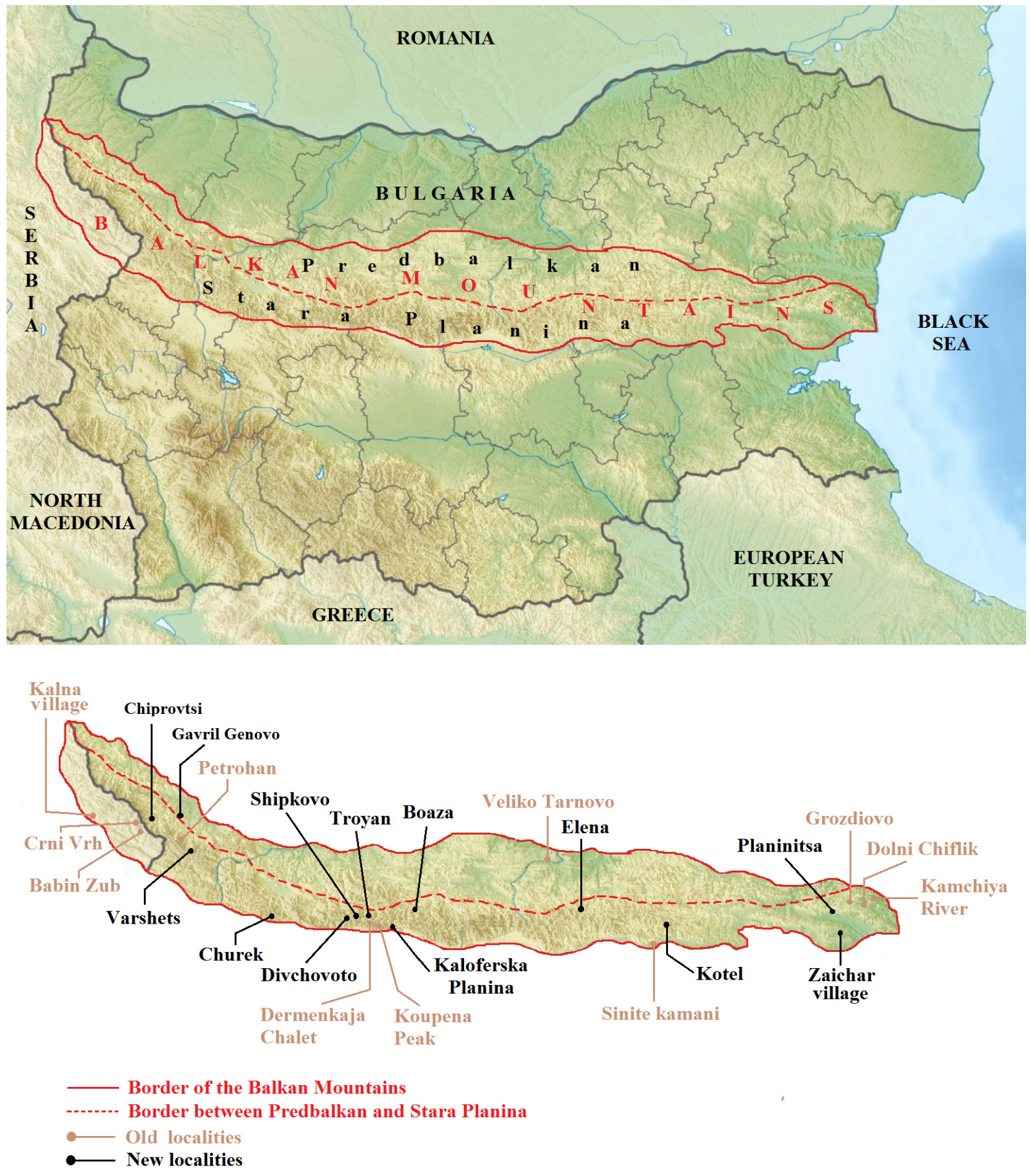

Fig. 1. Map of the Balkan Mountains with sites of collection.

Site 3: Gavril Genovo Village, 18.VI-15.VII.2020, 43.370698 N 23.063437 E, 362 m a.s.1., Malaise trap, I. Todorov.

Site 4: Churek Village, 20.VII.2020, $42.790991 \mathrm{~N}$ 23.729589 E, 889 m a.s.l., sweeping net, $M$. Kechev.
Site 5: Divchovoto Village, 28.VIII.2020, 42.821615 N 24.267189 E, 856 m a.s.1., sweeping net, M. Kechev.

Site 6: Shipkovo Village, 20.VII.2020, $42.881828 \mathrm{~N}$ 24.573756 E, $657 \mathrm{~m}$ a.s.1., sweeping net, M. Kechev. 
Diversity of long-legged flies (Diptera, Dolichopodidae) of the Balkan Mountains (Bulgaria and Serbia)

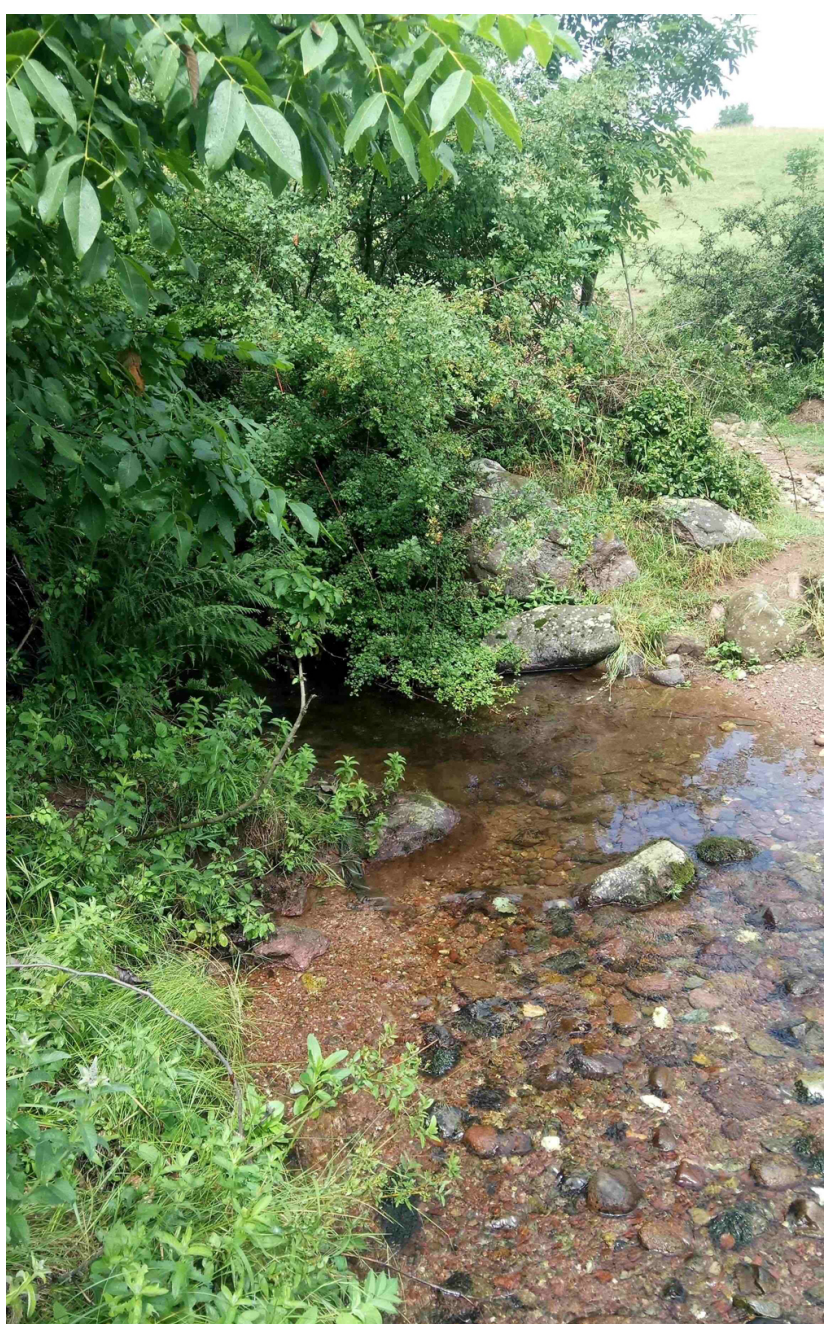

Fig. 2. River near Chiprovtsi.

Site 7: Kapincho Park near town of Troyan, 21.VII.2020, 42.883080 N 24.718593 E, 467 $\mathrm{m}$ a.s.l., sweeping net, M. Kechev. (Figs 3 and 4).

Site 8: Kaloferska Planina Mt, 42.641355 N 24.950285 E, $530 \mathrm{~m}$ a.s.l., Malaise trap, D. Ganeva \& T. Ljubomirov.

8a: 14.V-02.VI.2010.

8b: 20.VII-01.VIII.2010.

8c: 01.VIII-10.VIII.2010.

8d: 20.IX-2.X.2010.

Site 9: Boaza Place, 21.VII.2020, $42.894308 \mathrm{~N}$ $24.963426 \mathrm{E}, 437 \mathrm{~m}$ a.s.1., sweeping net, $\mathrm{M}$. Kechev.

Site 10: Elenska River, near the town of Elena, 21.VII.2020, 42.928457 N 25.711370 E, 443 $\mathrm{m}$ a.s.l., sweeping net, M. Kechev.

Site 11: Kotelska River, near the town of Kotel,

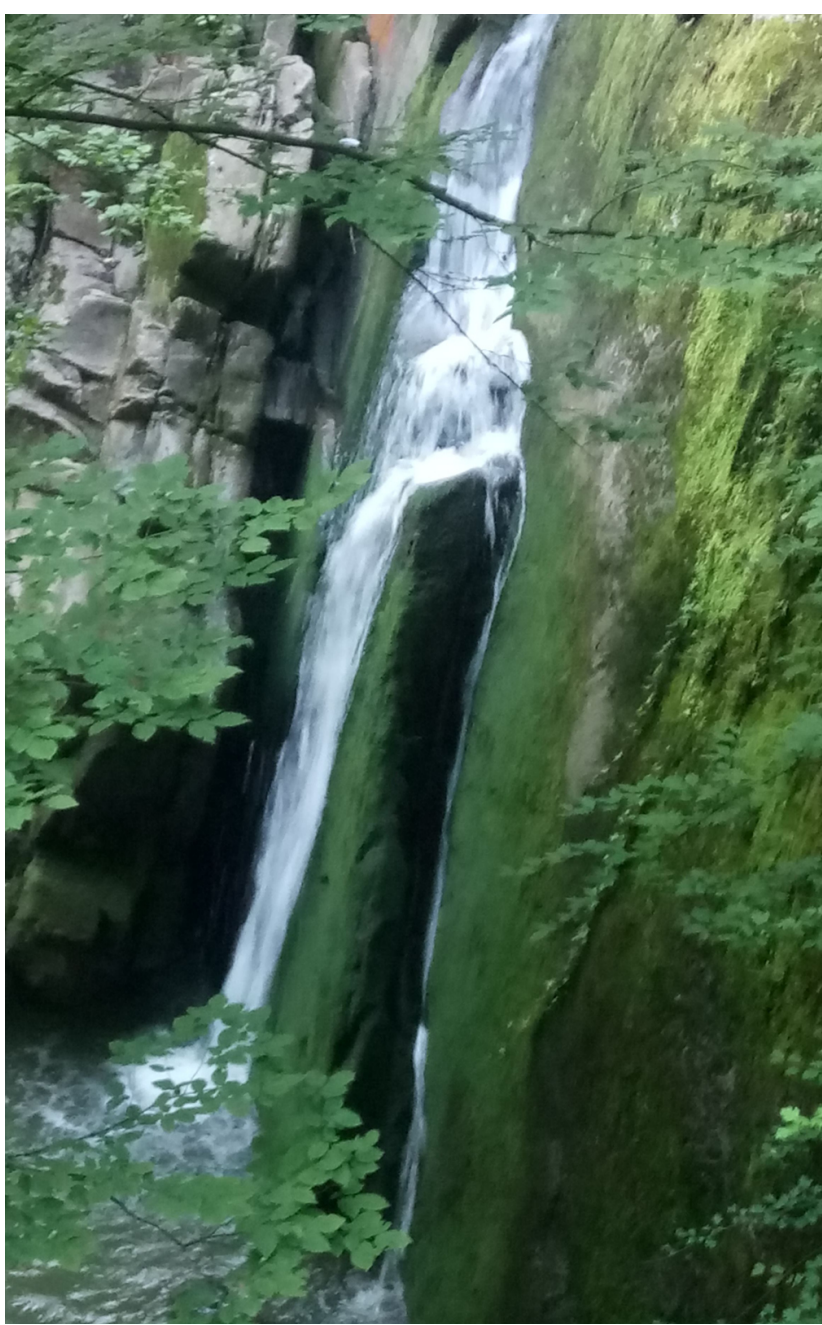

Fig. 3. Waterfall in the Kapincho Park near the Troyan Town.

29.VII.2020, 42.863379 N 26.480443 E, 444 $\mathrm{m}$ a.s.l., sweeping net, M. Kechev. (Fig. 5).

Site 12: Byala River, Zaichar Village, 27.VII.2020, 42.759319 N 27.143086 E, 477 m a.s.1., sweeping net, M. Kechev. (Fig. 6).

Site 13: Planinitsa Village, 27.VII.2020, 42.891613 N 27.172142 E, $242 \mathrm{~m}$ a.s.1., sweeping net, M. Kechev.

\section{Balkan Mountains}

The Balkan Mountains (Fig. 1) (Galabov, 1966; Glovnya \& Blagoeva, 1982; Hubenov, 1997), also called the Balkans, is a mountain range situated in the eastern part of the Balkan Peninsula. The Balkan range runs $557 \mathrm{~km}$ from the Vrashka Chuka Peak on the border between Bulgaria and Serbia eastward through 


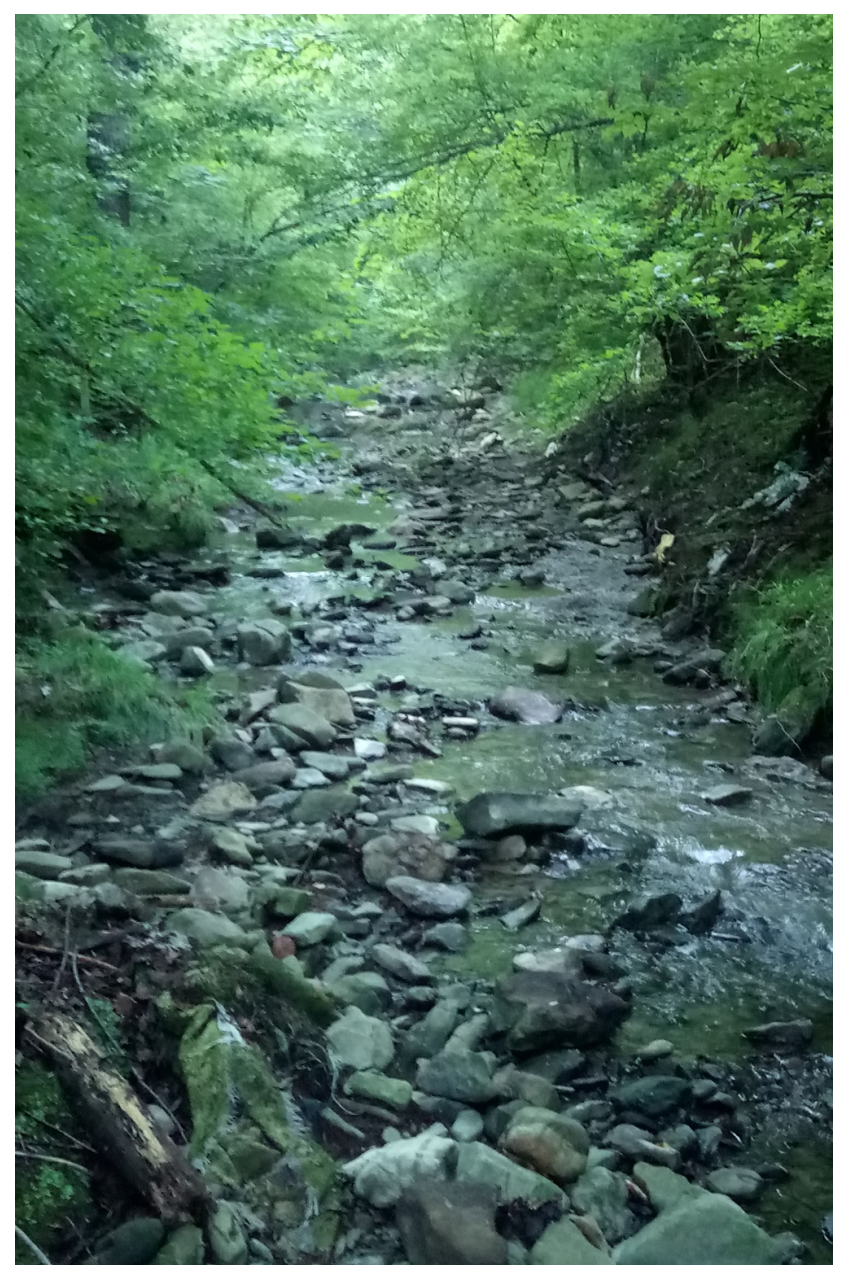

Fig. 4. River in the Kapincho Park near the Troyan Town.

central Bulgaria to Cape Emine on the Black Sea Coast.

Geologically, the Balkan Mountains are a mountain chain of fold mountains, a "young" part of the Alpine-Himalayan chain that stretches across most of Europe and Asia.

The Stara Planina (Balkan) range can be divided into three sections:

The Western Stara Planina extends from Vrashka Chuka to the Botevgrad Pass (Arabakonak) with a total length of 190 kilometres. The highest peak is Midzur (2169 m a.s.1.).

The Central Stara Planina runs from the Botevgrad Pass to the Vratnik Pass with a length of 207 kilometres. Botev Peak, the highest peak of the mountain ( $2376 \mathrm{~m}$ a.s.1.) is situated in this section.

The Eastern Stara Planina extends from the Vratnik Pass to Cape Emine with a length of 160 kilometres. The highest peak is Balgarka (1181 m a.s.l.).

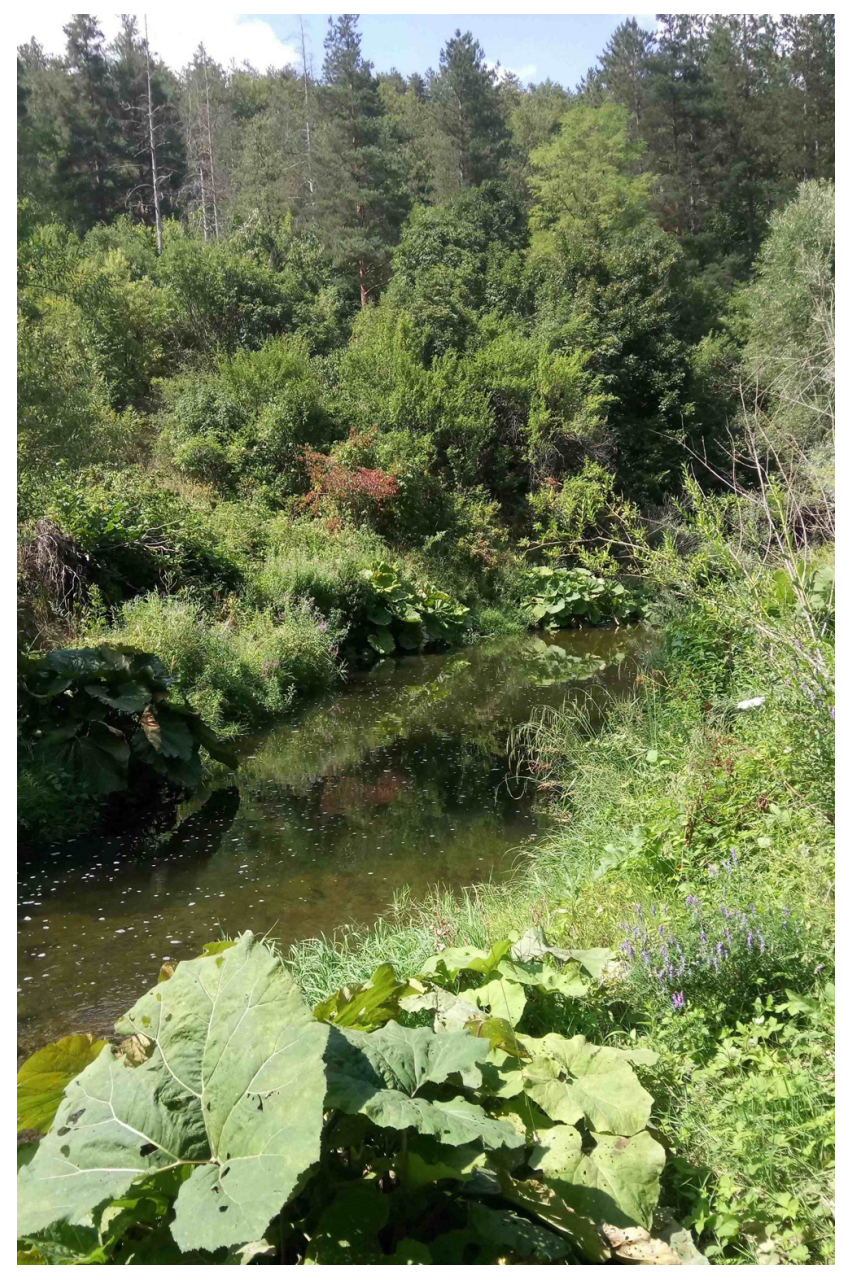

Fig. 5. Kotelska River.

\section{Faunistic results}

\section{DIAPHORINAE}

Argyra diaphana (Fabricius, 1775) - Serbia: Babin Zub (Grichanov, 2016).

Argyra ilonae Gosseries, 1989 - Serbia: Crni Vrh Village (Grichanov, 2016).

Argyra leucocephala (Meigen, 1824) - Material examined: Site 12: 1 male, 1 female. Note: First record for the Balkan Mountains.

Asyndetus latifrons (Loew, 1857) - Material examined: Site 1: 1 female. Note: First record for the Balkan Mountains.

Chrysotus angulicornis Kowarz, 1874 - Material ex- 
Diversity of long-legged flies (Diptera, Dolichopodidae) of the Balkan Mountains (Bulgaria and Serbia)

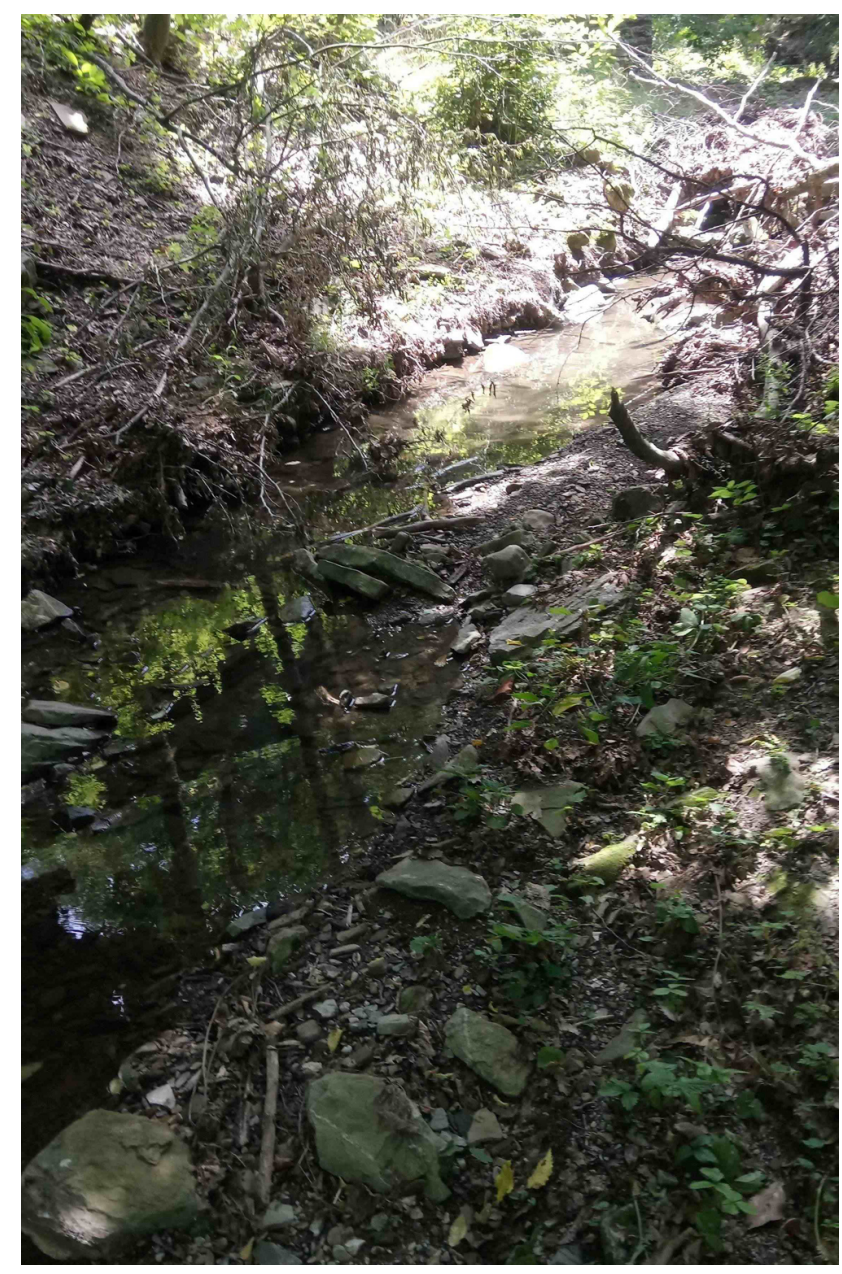

Fig. 6. Byala River near Zaichar Village.

amined: Site 12: 2 males. Note: First record for the Balkan Mountains.

Chrysotus cilipes Meigen, 1824 - Material examined: Site 8b: 1 female. Notes: First record for the Balkan Mountains.

Chrysotus femoratus Zetterstedt, 1843 - Bulgaria: Yantra River, Veliko Tarnovo (Kechev, 2017). New localities: Site 1: 1 male, 1 female; Site 4: 1 male; Site 10: 1 male.

Chrysotus gramineus (Fallén, 1823) - Material examined: Site 11: 1 male, 1 female. Note: First record for the Balkan Mountains.

Chrysotus laesus (Wiedemann, 1817) - Serbia: Babin Zub (Grichanov, 2016). New locality: Site 1: 2 males, 1 female.
Chrysotus obscuripes Zetterstedt, 1838 - Material examined: Site 8b: 1 male. Note: First record for the Balkan Mountains.

Chrysotus pennatus Lichtwardt, 1902 - Bulgaria: Yantra River, Veliko Tarnovo (Kechev, 2017).

Chrysotus suavis Loew, 1857 - Serbia: Kalna Village (Grichanov, 2016).

Diaphorus hoffmannseggi Meigen, 1830 - Serbia: Kalna Village (Grichanov, 2016).

\section{DOLICHOPODINAE}

Dolichopus campestris Meigen, 1824 - Bulgaria: Central Stara Planina Mts: Dermenkaja Chalet, $1500 \mathrm{~m}$ a.s.l. (Beschovski, 2013).

Dolichopus excisus Loew, 1859 - Bulgaria: East Stara Planina Mts: Sliven (Beschovski, 1967). New locality: Site 13: 1 male, 1 female.

Dolichopus lepidus Staeger, 1842 - Bulgaria: Central Stara Pl. Mts: Dermenkaja Chalet, $1500 \mathrm{~m}$ a.s.l. (Beschovski, 2013); Serbia: Babin Zub (Grichanov, 2016).

Dolichopus longicornis Stannius, 1831 (Fig. 7) - Material examined: Site 8c: 1 male. Note: First record for Bulgaria and second for the Balkan Peninsula.

Dolichopus longisetosus Negrobov, 1973 - Bulgaria: Petrohan Village (Beschovski \& Dzhambazov, 2002).

Dolichopus picipes (Meigen, 1824) - Bulgaria: Central Stara Planina Mts: Koupena Peak, $1600 \mathrm{~m}$ a.s.l. (Beschovski, 2013).

Dolichopus salictorum Loew, 1871 - Material examined: Site 2: 1 male. Note: First record for the Balkan Mountains.

Dolichopus ungulatus (Linnaeus, 1758) - Serbia: Babin Zub (Grichanov, 2016).

Gymnopternus aerosus (Fallén, 1823) - Material examined: Site 1: 1 male, 2 females. Note: First record for the Balkan Mountains. 


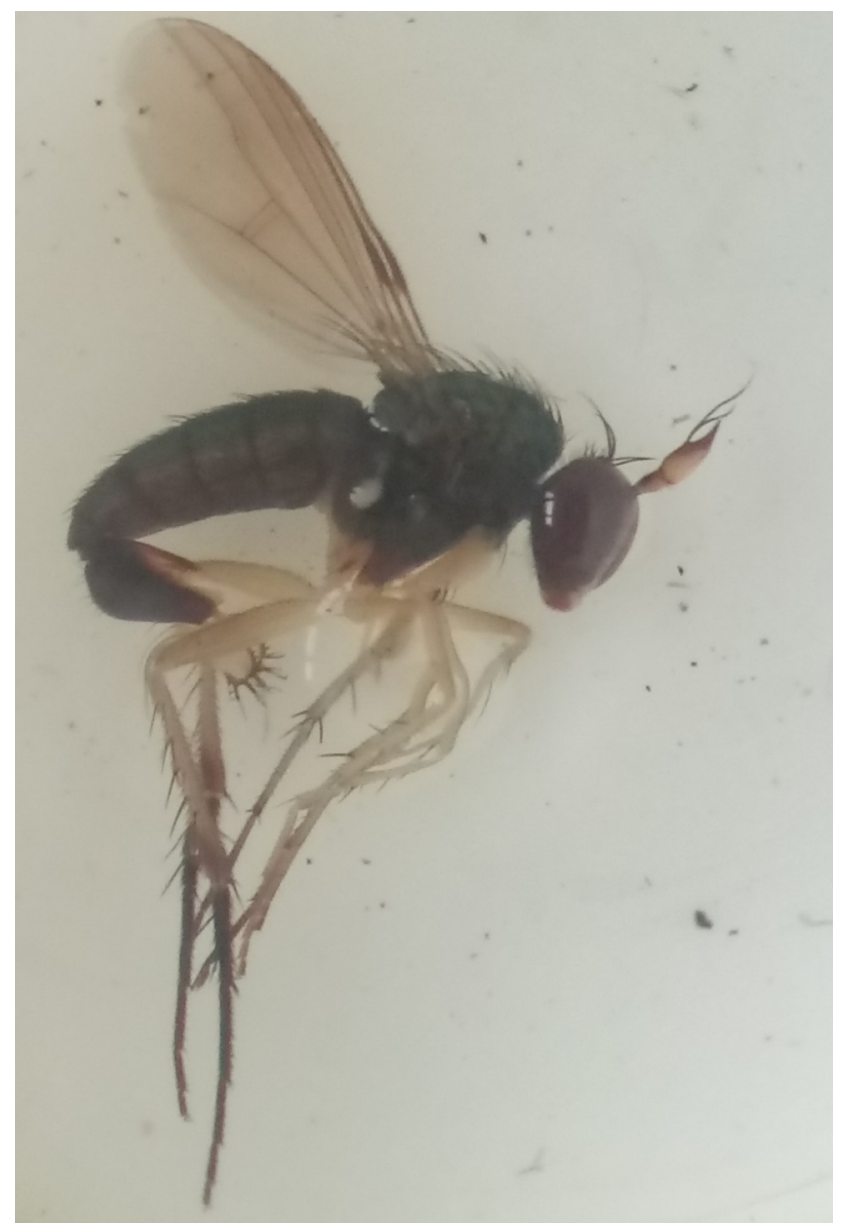

Fig. 7. Dolichopus longicornis Stannius, 1831.

Gymnopternus brevicornis (Staeger, 1842) - Serbia: Crni Vrh Village (Grichanov, 2016).

Gymnopternus celer (Meigen, 1824) - Serbia: Kalna Village (Grichanov, 2016). New locality: Site 6: 1 male, 14 females.

Hercostomus chetifer (Walker, 1849) - Material examined: Site 6: 1 male. Note: First record for Bulgaria.

Hercostomus nanus (Macquart, 1827) - Serbia: Kalna Village (Grichanov, 2016).

Hercostomus rusticus (Meigen, 1824) - Serbia: Babin Zub (Grichanov, 2016).

Poecilobothrus chrysozygos (Wiedemann, 1817) - Serbia: Kalna Village (Grichanov, 2016).

Poecilobothrus nobilitatus (Linnaeus, 1767) - Material examined: Site 8b: 1 male. Note: First record for the Balkan Mountains.

Sybistroma discipes (Germar, 1821) - Material examined: Site 6: 1 male. Note: First record for the Balkan Mountains.

Sybistroma impar (Rondani, 1843) - Bulgaria: Dolni Chiflik (Olejniček \& Barták, 1997).

Sybistroma obscurellus (Fallen, 1823) - Material examined: Site 5: 5 males, 1 female. Note: First record for the Balkan Mountains.

Tachytrechus genualis Loew, 1857 - Serbia: Kalna Village (Grichanov, 2016).

\section{HYDROPHORINAE}

Hydrophorus balticus (Meigen, 1824) - Bulgaria: Sliven, Sinite Kamani Natural Park (Kechev, 2017); Serbia: Stara Planina (Grichanov, 2016).

Hydrophorus praecox (Lehmann, 1822) - Bulgaria: Kamchiya River (Beschovski, 1964).

Liancalus virens (Scopoli, 1763) - Bulgaria: Sliven, Sinite Kamani Natural Park (Kechev, 2017); Serbia: Babin Zub (Grichanov, 2016). New localities: Site 4: 1 male; Site 6: 1 male.

\section{MEDETERANAE}

Medetera jacula (Fallén, 1823) - Serbia: Babin Zub (Grichanov, 2016). New locality: Site 8a: 1 male, 1 female; Site 8b: 2 males, 2 females; Site $8 \mathrm{~d}$ : 1 male, 1 female.

Medetera muralis Meigen, 1824 - Material examined: Site 8b: 1 male, 1 female. Notes: First record for Bulgaria.

Medetera pallipes (Zetterstedt, 1843) - Material examined: Site 3: 1 male, 1 female. Note: First record for Bulgaria and the Balkan Peninsula.

Medetera truncorum Meigen, 1824 - Serbia: Crni Vrh (Grichanov, 2016). 


\section{NEURIGONINAE}

Neurigona quadrifasciata (Fabricius, 1781) - Material examined: Site 3: 1 female. Note: First record for Bulgaria.

Neurigona pallida (Fallén, 1823) - Material examined: Site 8a: 1 male, 4 females. Note: First record for Bulgaria and second for the Balkan Peninsula. The species was previously known only from the Olympus Mts (Grichanov, 2009).

Neurigona suturalis (Fallén, 1823) - Material examined: Site 2: 1 male. Note: First record for the Balkan Mountains.

\section{RHAPHIINAE}

Rhaphium caliginosum Meigen, 1824 - Bulgaria: Sliven, Sinite Kamani Natural Park (Kechev, 2017); Serbia: Babin Zub and Kalna Village (Grichanov, 2016). New localities: Site 1: 3 females; Site 13: 1 male.

Rhaphium micans (Meigen, 1824) - Serbia: Crni Vrh (Grichanov, 2016).

Rhaphium riparium (Meigen, 1824) - Serbia: Kalna Village (Grichanov, 2016).

\section{PELOROPEODINAE}

Chrysotimus molliculus (Fallén, 1823) - Material examined: Site 8b: 1 male, 4 females; Site $8 \mathrm{c}$ : 5 females. Note: First record for the Balkan Mountains.

Peloropeodes acuticornis (Oldenberg, 1916) - Material examined: Site 9: 1 male. Note: First record for the Balkan Mountains.

\section{SCIAPODINAE}

Sciapus contristans (Wiedemann, 1817) - Bulgaria: Grozdiovo Village (Beschovski, 1967).

Sciapus costae Mik, 1890 (Fig. 8) - Material ex- amined: Site 8b: 5 males, 4 females; Site 8c: 1 female. Note: First record for Bulgaria and the Balkan Peninsula.

Sciapus opacus (Loew, 1866) - Bulgaria: Kamchiya River (Beschovski, 1971).

Sciapus platypterus (Fabricius, 1805) - Bulgaria: Yantra River, Veliko Tarnovo (Kechev, 2017). New localities: Site 8b: 1 mele, 1 female; Site 8c: 2 males; Site 10: 1 female.

\section{SYMPYCNINAE}

Campsicnemus curvipes (Fallén, 1823) - Serbia: Stara Planina, Mts Babin Zub (Grichanov, 2016). New localities: Site 5: 2 males, 1 female; Site 12: 1 male.

Campsicnemus scambus (Fallén, 1823) - Bulgaria: Grozdiovo Village (Beschovski, 1967).

Campsicnemus umbripennis Loew, 1856 - Serbia: Babin Zub (Grichanov, 2016).

Sympycnus pulicarius (Fallén, 1823) - Bulgaria: Sliven, Sinite Kamani Natural Park (Kechev, 2017). New locality: Site 2: 1 male.

Syntormon denticulatum (Zetterstedt, 1843) - Serbia: Kalna Village and Crni Vrh (Grichanov, 2016).

Syntormon pallipes (Fabricius, 1794) - Bulgaria: Kamchiya River (Beschovski, 1964); Sliven, Sinite Kamani Natural Park (Kechev, 2017); Serbia: Crni Vrh and Babin Zub (Grichanov, 2016). New locality: Site 5: 1 female; Site 11: 1 male.

Teuchophorus medovoensis Kechev, Negrobov \& Grichanov, 2014 - Material examined: Site 6: 1 male; Site 7: 3 male; Site 9: 7 males, 5 females. Note: First record for the Balkan Mountains.

Teuchophorus monacanthus Loew, 1859 - Bulgaria: Yantra River, Veliko Tarnovo (Kechev, 2017).

Teuchophorus simplex Mik, 1880 - Material examined: Site 6: 1 male, 1 female; Site 7: 2 males, 1 female; Site 9: 1 male, 1 female. Note: First record for the Balkan Mountains. 

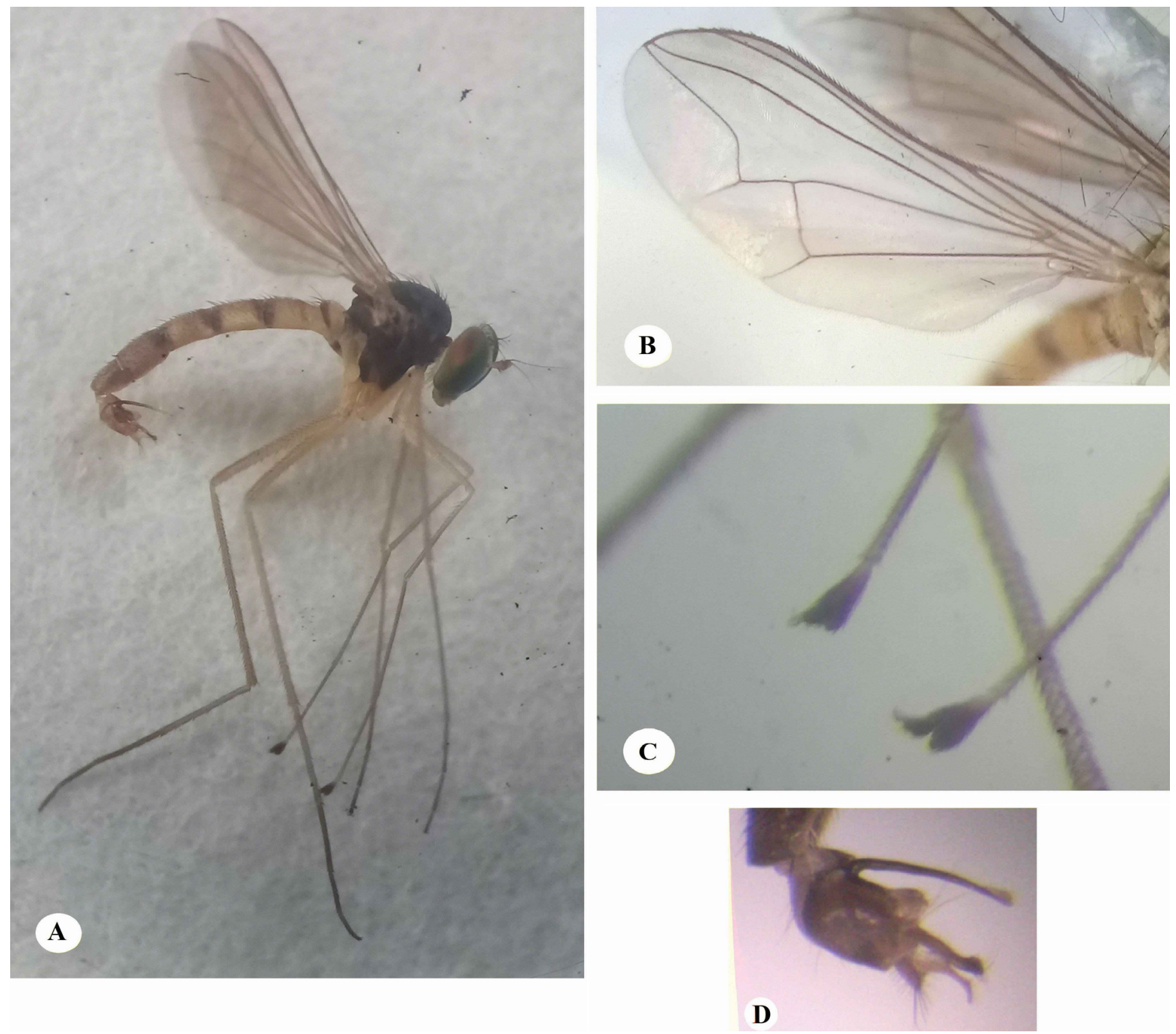

Fig. 8. Sciapus costae Mik, 1890: (A) habitus, (B) wing, (C) fore tarsi, (D) hypopygium.

\section{Discussion}

This paper presents information about 61 dolichopodid species, belonging to twenty-two genera and nine subfamilies found in the Balkan Mountains. Twenty-two species collected from 13 localities are recorded as new for the studied area, seven of which (Dolichopus longicornis, Hercostomus chetifer, Medetera pallipes, M. muralis, Neurigona quadrifasciata, N. pallida and Sciapus costea) are new to the fauna of Bulgaria. Medetera pallipes and Sciapus costea are also new for the Balkan Peninsula. With the new records for Bulgaria, the number of the dolichopodids in the country in- creases to 204 species. The total number of known species for the Balkan Mountains is 61 so far.

For the species Chrysotus obscuripes, Medetera jacula, Peloropeodes acuticornis, Teuchophorus simplex and T. medovoensis this study provides the second localities in Bulgaria. Teuchophorus medovoensis was described in 2014 from the Sarnena Sredna Gora Mountain with one male specimen (Kechev et al., 2014). Three years later, Kechev (2016) reported another male specimen from the same mountain and locality very close to the first one. This work gives three new localities of this species in the Balkan Mountains, collected at the same altitude as the type locality. The 
species Sciapus costae is known only from Italy, France, Morocco and Tunisia (Grichanov \& Negrobov, 2014). This survey expands the area of distribution of the species and provides the easternmost locality of $S$. costae so far.

The dolichopodids inhabit mostly humid places and all localities of collection in this survey, except Gavril Genovo, are in the vicinity of rivers and streams in the Balkan Mountains. The species found in Gavril Genovo are collected from an oak forest with lower humidity.

The study of predatory flies of the family Dolichopodidae in the Balkan Mountains is still insufficient and new surveys are needed. This work gives base for further investigations and it is probable that the real number of dolichopodids in this region will reach $140-150$ species or more.

\section{Acknowledgements}

This work is dedicated to the Russian dipterist Prof Dr Sc Oleg Pavlovich Negrobov (Novermber 21, $1941-$ January 8, 2021) for his help and advices to me. Thanks are due to Dr Mario Langourov from the National Museum of Natural History, Sofia and Dr Ivailo Todorov, Dr Toshko Ljubomirov, both from the IBER, Sofia, as they provided me with material collected by them from the Varshets Village, Gavril Genovo Village and the Kaloferska Planina Mt. Special thanks to Halilibryam Ramadan Halilibryam from the State Forest Enterprise in the town of Aytos, who helped me with the collecting trip along the banks of the Byala Reka near the Zaichar Village. I also express my gratitude to Mariya Mihaylova for converting the picture and drawings into relevant dpi. This work has been carried out in the framework of the National Science Program "Environmental Protection and Reduction of Risks of Adverse Events and Natural Disasters", approved by the Resolution of the Council of Ministers 577/17.08.2018 and supported by the Ministry of Education and Science (MES) of Bulgaria (Agreement D01 230/06.12.2018).

\section{References}

Beschovski V. 1964 Beitrag zum Studium der halobionten und halophilen Dipteran Brachycera vom Bulgarischen Küstenbereich des Schwarzen Meeres. Zoologischer Anzeiger 172 (4): 261-264.
Beschovski V. 1967 Für die Fauna Bulgariens bislang unbekannte Dolichopodidae (Dipt.). Zoologischer Anzeiger 178 (3/4): 219-224.

Beschovski V. 1971 A contribution to the dipteran fauna (Diptera, Brachycera) at the Bulgarian Black Sea Coast. Bulletin de l'Institut de zoologie et musée 33: 5-11. (In Bulgarian)

Beschovski V. 2013 Dolichopus species (Diptera: Dolichopodidae) in the Entomological Collection of the Institute of Biodiversity and Ecosystem Research at the Bulgarian Academy of Sciences. ZooNotes 38: 1-4.

Beschovski V., Dzhambazov B. 2002 Dolichopodidae taxa known and new to the Bulgarian fauna (Diptera: Empidoidea). Acta zoologica bulgarica 54 (1): 19-26.

d'Assis Fonseca E.C.M. 1978 Diptera, Orthorrhapha, Brachycera, Dolichopodidae. Handbooks for the Identification of British Insects. Royal Entomological Society of London, London, 90 pp.

Galabov Zh. 1966 Stara Planina chain system. In: Gerasimov, I.P. (ed.) Geography of Bulgaria. Physical geography, vol. I. Bulgarian Academy of Sciences, Sofia, 548 pp.

Glovnya M., Blagoeva E. 1982 Physical geography of the continents. Nauka i Izkustvo Publishing House, Sofia, 566 pp. (In Bulgarian)

Grichanov I. 2007 A checklist and keys to Dolichopodidae (Diptera) of the Caucasus and East Mediterranean. VIZR RAAS (Plant Protection News Supplement), St Petersburg, Russia, 160 pp.

Grichanov I. 2009 New records for Mediterranean Dolichopodidae (Diptera). An international journal of dipterological research 20 (4): 207-215.

Grichanov I. 2016 On the Dolichopodidae (Diptera: Empidoidea) from Serbia. Acta entomologica serbica 21: 27-37.

Grichanov I., Negrobov O.P. 2014 Palaearctic species of the genus Sciapus Zeller (Diptera: Dolichopodidae). VIZR RAAS (Plant Protection News Supplement), St Petersburg, Russia, 85 pp.

Hubenov Z. 1997 Possibilities for using of a system from the really defined natural territories for the faunistic researches in Bulgaria. Acta zoologica bulgarica 49: 5-9.

Kechev M. 2016 Forestry and riparian Long-legged flies (Diptera: Dolichopodidae) from Sarnena Sredna Gora Mountain with new records for Bulgaria. Silva balcanica 17 (2): 45-55.

Kechev M. 2017 Predatory Long-legged flies (Diptera, 
Empidoidea, Dolichopodidae) from the Yantra River and "Sinite kamani" Natural Park, Bulgaria. New knowledge Journal of scence 6 (4): 115-118.

Kechev M., Negrobov O., Grichanov I. 2014 Diversity of long-legged flies (Diptera: Dolichopodidae) along the banks of the Omurovska river (Bulgaria), with the description of a new species of the genus Teuchophorus Loew. Acta zoologica bulgarica 66 (3): 317-323.

Negrobov O., Stackelberg A.A. 1969 Dolichopodidae. In: Stackelberg A.A., Narchuk E.P. (eds) Opredelitel nasekomyh Evropejskoj chasti SSSR., T.5, ch. 1: Dvukrylye, blokhi. Nauka, Leningrad, pp. 670-752. (In Russian)
Olejniček J., Barták M. 1997 Some faunistically interesting Dolichopodidae (Diptera) from Europa. In: Vaňhara, J., Rozkošny, R. (eds), Dipterologica bohemoslovaca. Vol. 8. Folia Facultatis Scientiarium Naturalium Universitatis Masarykianae Brunensis, Biologia 95: 137-139.

Parent O. 1938 Diptères Dolichopodidés. Faune de France 35: 1-720. 